Article

\title{
Digital Teaching, Inclusion and Students' Needs: Student Perspectives on Participation and Access in Higher Education
}

\author{
Leevke Wilkens $^{1, *}$, Anne Haage ${ }^{2}$, Finnja Lüttmann ${ }^{2}$ and Christian R. Bühler ${ }^{1}$ \\ ${ }^{1}$ Rehabilitation Sciences, Rehabilitation Technology, TU Dortmund, Germany; \\ E-Mails: leevke.wilkens@tu-dortmund.de (L.W.), christian.buehler@tu-dortmund.de (C.B.) \\ 2 DoBuS-Department of Disability and Studies, TU Dortmund, Germany; E-Mails: annegret.haage@tu-dortmund.de (A.H.), \\ finnja.luettmann@tu-dortmund.de (F.L.) \\ * Corresponding author
}

Submitted: 1 February 2021 | Accepted: 10 May 2021 | Published: 21 July 2021

\begin{abstract}
In this article we discuss the contribution of digitalisation for equal participation in higher education. Its potential is often postulated, but accessibility is seldom examined in this context. Despite the challenges and difficulties created in the summer term of 2020, this semester has provided a great opportunity to collect data on digital teaching, as face-to-face teaching needed to be transformed into digital teaching. Based on two surveys conducted in the summer of 2020, current practices and students' needs regarding accessibility are outlined. Despite the circumstances, it can be derived from the surveys that digital teaching generally provides a variety of advantages for students with disabilities, although some tools and platforms remain not fully accessible to them. Additionally, the results indicate that not only students with sensory impairments benefit from the principles of the Web Content Accessibility Guidelines (2018). In particular, the principles 'operable' and 'understandable' are beneficial for students with mental health difficulties. Regarding the assessment of accessibility features, the study shows that the perception of students with and without impairments is very similar.
\end{abstract}

\section{Keywords}

accessibility; digital teaching; disability; higher education; ICTs; impairment; inclusion; universal design; WCAG

\section{Issue}

This article is part of the issue "Inclusive Universities in a Globalized World" edited by Liudvika Leišyte (TU Dortmund, Germany), Rosemary Deem (Royal Holloway, UK) and Charikleia Tzanakou (Oxford Brookes University, UK).

(C) 2021 by the authors; licensee Cogitatio (Lisbon, Portugal). This article is licensed under a Creative Commons Attribution 4.0 International License (CC BY).

\section{Introduction}

Our contribution to this thematic issue deals with the following research question: To what extent do digital learning environments contribute to equal participation in higher education? Therefore, this article (1) aims to outline barriers in current practices, especially for students with disabilities, and (2) tries to figure out how principles of Universal Design (UD) and accessibility may contribute to equal participation for all students. Based on two recent surveys conducted during the summer of 2020, students' perspectives on digital teaching as well as their expectations and experiences concerning digital learning environments will be examined.
Conflating these two studies can thus be used to research the need for accessible digital media from two different angles. The first perspective is based on UD and examines how its principles in digital learning environments can be used to improve studying for all students (CAST, 2018). The second perspective focuses on the experiences of students with disabilities regarding the digital tools and platforms they had to use during the digital semester in summer 2020. Thus, particular challenges and opportunities of digital studying for this target group can be outlined.

Although digitisation is a task that German universities have assigned a high priority, it has only partially arrived in teaching. In a 2018 survey of university 
administrators, not even one-third of the respondents estimated that the implementation of digitisation in teaching was well advanced (Gilch et al., 2019). Due to the Covid-19 pandemic, digital teaching suddenly became indispensable and without alternative. Instructors who had previously used learning management systems (LMS) at most for filing presentations now had to organise all learning activities via LMS and other digital tools. Students were also new to many of the tools and features of LMSs. This transition, therefore, provided an opportunity to obtain more data on the accessibility and usability of existing platforms and tools. Additionally, the number of students with experiences using digital tools in various settings has increased.

At the same time, the current situation remains exceptional. Those who were inexperienced in digital teaching or studying were given hardly any time to familiarise themselves with the tools (Scott \& Aquino, 2020; Wilson et al., 2020). In addition, the learning environment and social life at the university have changed dramatically (Traus et al., 2020). The university as a place of learning was closed to the students, who were henceforth entirely dependent on their own digital equipment. This was particularly challenging for students with disabilities if they rely on assistive technologies but are not adequately equipped at home (Breitenbach, 2021). They had to use various digital formats that were new to them but could not access the university's counselling services. Also, social distancing measures made it difficult to work with personal assistants (Zhang et al., 2020).

The pandemic situation has also affected many students' financial and housing situation (Arndt et al., 2020; Breitenbach, 2021; Traus et al., 2020). Especially for students with disabilities, this has also been associated with health concerns, as many of them belong to the Covid-19 risk group. These are not favourable conditions for the potential of digital media for equal participation to take effect in higher education, as attested by research. Therefore, it is important to distinguish between the effects attributed to the pandemic and the positive or negative practical experiences of this 'forced digitisation' that can be meaningfully implemented in teaching practice under 'normal' circumstances.

\section{Theoretical Framework}

\subsection{Digitalisation}

By now, every aspect of our everyday life is affected by digitalisation (Persike \& Friedrich, 2016). Terms such as digital society or digital epoch (Kerres, 2020) illustrate how closely linked technological and social processes of change are and how far-reaching they are. Digitalisation primarily describes technical aspects, which have a profound impact on virtually every area of life. However, digitalisation is both part and driver of broader social change. Both developments-media change and social changeare mutually dependent (Krotz, 2014).
The university is assigned a dual function as "user of digital opportunities and at the same time driver of digital development" (Sekretariat der Kultusministerkonferenz, 2016, p. 44). In higher education, digital media enables location- and time-independent studying, access to means of individual and lifelong learning. At the same time, digitalisation helps open higher education to target groups that cannot study exclusively at a face-to-face university due to their living conditions, such as care responsibilities, health issues, students with employment (Hochschulforum Digitalisierung, 2015). Digitalisation can expand learning spaces and promote improved access to knowledge and education individually and globally. Open education and open educational resources, among others, endorse this (Hofhues, 2020; Kerres, 2020).

In fact, digital teaching and learning formats can serve to promote equal participation for previously disadvantaged and marginalised groups. This is especially relevant for students with disabilities. Learning materials can be designed to be accessible for students with sensory impairment, time sovereignty allows working on material at one's own pace, and communication processes can also be restructured more inclusively, e.g., reducing attendance requirements or making different communication channels available (Zorn, 2018).

However, this requires adherence to the principles of UD and accessibility in the selection and design of digital platforms, programmes and tools.

But "new educational ICT services are seldom fully accessible" (Bühler et al., 2020, p. 129). Nevertheless, accessibility of digital learning environments is only the first step since learning materials and didactics must also be appropriately accessible and sensitive towards diverse learning conditions (Bühler et al., 2020; Emmerdinger et al., 2018).

In Germany, the discourse regarding the digitalisation of teaching is primarily conducted in terms of educational technology: Which set of tools and media can improve studying and learning as well as teaching? Expectations are usually high, often presuming that the digital tool's mere implementation will automatically resolve teaching problems. As a result, educational practices are not adjusted, but old practices are optimised using modern tools. Unsurprisingly, critical responses warn against such a technology-deterministic view: "Educational potential is wasted by focusing on the digital. Too little attention is paid, for example, to assumptions about the use and effects of media or frameworks and structures for teaching and learning, especially in educational institutions" (Schiefner-Rohs \& Hofhues, 2018, p. 251). This perspective wants to emphasise an issue which is too often left unconsidered: namely, the question of whether teaching-learning practices are changing in this context, become more open, and to what extent the relationship between teachers and learners is affected by that (Schiefner-Rohs \& Hofhues, 2018). 


\subsection{Universal Design and Accessibility in Higher Education}

Higher education has changed in recent years. Through the ratification of the UN Convention on the Rights of Persons with Disabilities (UN-CRPD) in 2009, in which the participation of all people is stipulated in Art. 24, universities, as part of the education system (tertiary education), now bear the responsibility to enable participation for a heterogeneous student group (Dannenbeck et al., 2016). This responsibility is also enshrined in the fourth goal of the United Nations SDGs on quality education. A key factor towards achieving this goal is to conceive inclusive learning spaces-both physical and digital (United Nations Educational, Scientific and Cultural Organization, 2017). Another step forward in the direction of accessible digital teaching is the EU Directive of 26 October 2016 (2016) "on the accessibility of the websites and mobile applications of public sector bodies." This directive is transposed into national law (e.g., BITV in Germany). It makes the deployment of accessible digital learning materials, tools, etc. for institutions of the public sector, including universities, mandatory.

UD is a much-cited model for inclusive (university) teaching (Bartz, 2020; Burgstahler et al., 2020; Dalton et al., 2019).

Today's understanding of UD is based on its conception by the Center for Universal Design. The architect Ronald Mace introduced the term to establish a concept that meets "the needs of as many users as possible" (Center for Universal Design, 1997). According to the UN-CRPD:

'Universal Design' means the design of products, environments, programmes and services to be usable by all people, to the greatest extent possible, without the need for adaptation or specialised design. 'Universal design' shall not exclude assistive devices for particular groups of persons with disabilities where this is needed. (United Nations, 2008, Article 2)

With an emphasis on diversity, inclusiveness and accessibility, UD comprises seven principles concerning the design of products and environments (Center for Universal Design, 1997):

- equitable use

- flexibility in use

- simple and intuitive use

- perceptible information

- tolerance for error

- low physical effort

- size and space for approach and use

There are different approaches to the use of UD in (higher) education. According to Fisseler and Markmann 2012), these seven principles can be adopted and applied in education as such, modified and expanded, or completely transformed into new ones.

Universities make use of UD mainly in the form of its following variations: Universal Design for Learning (UDL) and Universal Design for Instruction (UDI). Both models are based on UD and are a proactive framework to support inclusive learning and teaching.

UDL emerged from UD and focuses on creating accessible learning environments to meet the individual needs of students with different conditions/ backgrounds. It aims to create a learning atmosphere that reduces the obstacles experienced and supports individual learning strategies (Burgstahler et al., 2020). UDL offers specific tools and methods to integrate the UD principles into the respective learning and educational environment. UDL is defined as a "research-based set of principles that together form a practical framework for using technology to maximise learning opportunities for every student" (Rose \& Meyer, 2002, p. 5). By including the nature of the user and their different educational needs, UDL established three core elements that make education accessible. According to the UDL, education should include different means of representation and offer learners various ways to acquire knowledge or skills. Learners should be provided with several options to perceive and comprehend information. Education should also include different means of action and expression, introducing alternatives for students, such as physical activity or different tools to express their knowledge. Finally, education should address differences by considering the learners' interests and specific challenges as well as offer multiple means of action and engagement. This idea aims at helping students to optimise their learning process by enhancing their range of individual choices and thus enabling them to develop a sufficient level of self-reflection (CAST, 2018).

Another approach in higher education based on UD is UDI, a tool for planning courses and recording learning outcomes against the background of the increasing hetereogeneity of the student body in higher education. To do so, Scott et al. (2003) modified the seven principles of UD and added two more. The principles of UDL and UDI can be implemented and promoted through digital media (Fisseler \& Markmann, 2012). In particular, students with disabilities can benefit from the multimodality of digital media.

Digitalisation is seen as having a great potential for inclusion. Nevertheless, to make use of this potential, a variety of aspects need to be considered. That includes digital media, its accessibility and accessibility of the (digital) environment and the didactic concept. With its different modifications, UD is one recognised concept to design inclusive teaching. Additonally, when teaching with UD principles in mind, accessibility has to be considered. For example, when using a video without audio description and captions, the video itself may satisfy the first principle of UDL, i.e., "provide multiple means of representation" (CAST, 2018), while at the same time 
excluding students who need audio description or captions. Only an accessible video fulfils the first principle of UDL for all students (Thompson, 2015). Thus, digitalisation and UD provide the context for research on accessibility issues, which can be seen as a success factor when aiming for an inclusive university.

\section{State of the Art}

In addition to socio-political discourses as outlined before, studies show that an increasing heterogeneity characterises students at universities. Globally, statistics indicate a growing number of students with disabilities enrolling in higher education (Fichten et al., 2020). To address this development, digital media and e-learning are closely linked to developing potentially equal opportunities for participation in higher education-they offer new possibilities for learning, access to information and communication. By now, Web 2.0 technologies and complementary learning technologies are omnipresent in higher education. Students engage in various forms of e-learning every day, e.g., course registration, library use and distributed online course materials (Kumar \& Owston, 2016). Despite these potentials and the already existing media usage, new barriers to education may emerge and, in turn, exclude people. Therefore, Zorn (2018) criticises that the e-learning discourse often excludes aspects of inclusion and that the two perspectives, e-learning and inclusion, are rarely considered together. This dilemma clearly shows that digitalisation in higher education requires an appropriate and well-thought-out overall concept (Arnold et al., 2018). Edelmayer and Rauch (2018) state that even though fundamental knowledge concerning the technical principles of accessibility has been available for quite a long time, its realisation and implementation has indeed been very slow and remains incomplete until today.

Nevertheless, institutions of higher education are responsible for providing accessible ICTs. It is essential to include the needs of students with disabilities in development processes to ensure positive learning experiences for all students (Fichten et al., 2020). Students' impairments influence their use of technologies (Fichten et al., 2012), and their use of technologies, in turn, influences their studying processes: If students face difficulties using technologies, their studies will also prove to become increasingly difficult (Kumar \& Owston, 2016). For an inclusion-oriented university, it cannot be emphasised enough that accessible technologies not only offer advantages to students with disabilities but that an accessible learning management system compensates for various (temporary) difficulties, such as a poorly lit workstation, a broken touchpad and no existing mouse (Kumar \& Owston, 2016). Nevertheless, the question Burgstahler (2015a, p. 69) posed still stands: "Online learning opens doors to education for everyone who has access to the technology required to participate. Or does it?"
It is not enough to provide university teaching via digital media, and the abovementioned potentials will fulfil themselves. Instead, various efforts are necessary.

Fernandez (2019, p. 2) points out that, especially in tertiary education, "ableist dynamics and 'disabling' ideologies" still shape the spaces in which teaching and learning take place. Often, the technologies used are not holistically designed with accessibility in mind (Burgstahler, 2015a), and improvements are always costly and time-consuming (Bühler et al., 2020). Even though it is emphasised in various instances that accessibility is advantageous for all students, hardly any studies can be found which explicitly address accessibility when examining the use of digital media (Grosch, 2012; Schmid et al., 2017; Steffens et al., 2017). Scientific work in the higher education context that explicitly addresses media accessibility is often conceptual rather than empirical (Burgstahler, 2015b; Fichten et al., 2020) or focuses on singular types of impairment, such as autism (Adams et al., 2019), intellectual impairment (Arachchi et al., 2017) or visual impairment (Köhlmann, 2017). However, since accessibility and usability directly impact the pedagogical effectiveness of e-learning systems and resources for all learners, especially those with disabilities, both aspects should be considered in all e-learning projects equipollent (Cooper et al., 2007).

\section{Methods}

During the summer term of 2020, two student surveys on the accessibility of digital teaching were conducted at TU Dortmund: One was part of a research project concerned with the development of a video-based learning platform in teacher education (Degree survey). The second one dealt with the conversion to digital teaching due to the pandemic situation and aimed only at students with impairments (DoBuS survey).

TU Dortmund was founded 52 years ago and encompasses 16 faculties "ranging from science and engineering to social sciences and culture studies. The university has about 33,440 students and 6,500 employees, including 300 professors" (TU Dortmund, 2021a). It follows an inclusive strategy and runs a support and counselling service for people with disabilities (DoBuS). The staff unit at "Equal Opportunities, Family and Diversity," together with DoBuS, initiates various processes to compensate for structural disadvantages, such as the inclusion of disadvantaged compensation for students with disabilities/chronic illnesses and students with children in all examination regulations and the design of an accessible campus plan (Stabsstelle Chancengleichheit, Familie und Vielfalt, 2021). On the campus itself, DoBuS offers a workspace where students can work with assistive technology scientifically on PCs equipped specifically for people with disabilities. Disability-experienced staff counsel and instruct students to use appropriate assistive devices in coordination with the software used in their studies. Additionally, in the library, there are rooms 
equipped with a $\mathrm{PC}$ adapted to the needs of students with visual impairment (DoBuS, 2021). Also, the Office of University Sports states on its webpage that they try to provide conditions so that everyone can participate instead of providing special courses, such as wheelchair sports (Hochschulsport Dortmund, 2021). Furthermore, DoBuS offers students counselling and support services to be used during their studying time (TU Dortmund, 2021c). During the pandemic, the university had to close the buildings and all teaching was transferred to distance teaching (TU Dortmund, 2021b).

In the context of the research project "Degree 4.0Digital Reflexive Teacher Education 4.0: Video-BasedAccessible-Personalized," the subproject "Rehabilitation Sciences" developed a questionnaire addressing the assessments and needs of students with and without impairment regarding their desired components for a learning platform that was under development at the time. The questionnaire is partly based on questionnaires which have already been used to conduct study-related media use and disability, e-learning problems and solutions (Fichten et al., 2009; Zawacki-Richter et al., 2016). Questions and items consisting of accessibility aspects based on the Web Content Accessibility Guidelines (WCAG; see World Wide Web Consortium [W3C], 2018) and sociodemographic questions, items regarding difficulties in studies and student-related impairment were added as well. The survey was sent to all student teachers at TU Dortmund. On the one hand, because the exact number of students with impairments is unknown, on the other hand, because accessibility can be advantageous to all students (Kumar \& Owston, 2016). Additionally, a universally designed product can be used by a target group that is as heterogeneous as possible.

\subsection{Degree Survey Sample}

The questionnaire was sent to 6,411 student teachers at TU Dortmund via mail. The survey period was from June to August. In total, 507 students took part in the survey, with 408 finishing it. Fifty-eight students (11.4\%) identified themselves as having a student-related impairment, a number that matches the 21st Social Survey by Middendorf et al. (2017), i.e., 11\%.

\subsection{DoBuS Survey Sample}

The second survey was initiated by DoBuS. To find out how students with impairments or chronic illnesses evaluate the rapid transition towards digital teaching during the summer term of 2020, they conducted an online survey among students with an impairment who use their service. The questionnaire itself was developed to align these services with the needs of students with impairments and chronic illnesses and the challenges that arose from the cutover to digital teaching. It comprises 22 questions, which were recorded both in the form of a 4-6 digits Likert scale and in the form of open response for- mats. The survey asked about the advantages and disadvantages of digital study to digital teaching during the pandemic and the transition to the relevant tools and study materials.

Twenty-one students participated in the survey, most of whom reported visual impairment or blindness (12 participants), 5 reported a mental impairment, 4 reported a chronic somatic illness, 3 reported a mobility impairment and 1 report other impairments. Four of the respondents reported multiple impairments, and seven stated their belonging to the Covid-19 risk group.

\section{Results}

To address the question raised in this thematic issue, on how accessible and barrier-free contemporary universities for students with disabilities are, it is important to research the question of who benefits from accessible universities.

Rather than surveying the number of students who had stated that they had a disability, we asked which specific difficulties they have encountered so far and continue to encounter while studying in the Degree survey. Thus, the assessments and needs of students with and without impairments were addressed. The results show that for $40 \%$ to $46 \%$ of all students, some difficulties impede their studies, such as organisational matters, assessments, study materials or participation in lectures.

For example, about one-fifth of the students cannot regularly attend classes: Some have to work (11\%) or have family care responsibilities (5\%). The external circumstances of many lectures also constitute barriers: For instance, for $54 \%$ of all students, noise and disturbances are severe problems, and every fourth respondent describes concentration problems during a 90-minute lecture. For about half of the students, another difficulty is the lack of study materials for followup studying.

Students with impairments are significantly more affected by conditions that complicate studying processes: Three-quarters report problems concerning study organisation, $36 \%$ are not able to attend classes regularly. Two-thirds report concentration problems during seminars, $72 \%$ have difficulties with noise and disturbance, and almost $90 \%$ lose pieces of information when it is presented in an exclusively verbal manner during lectures (Degree survey; see Figure 1).

By now, it has become widely known that most of these difficulties can be compensated or at least reduced through the implementation of digital media. When being asked about their perception of possible benefits of digital teaching at university, significantly more students with impairments indicated that they were better able to compensate for the lack of face-to-face teaching (CramersV [CrV] 0.176, $p=0.005$ ), that they were able to both process recorded events at their own pace (CrV 0.158, $p=0.011$; all impairment types except students with hearing impairment), and intercept timetable 


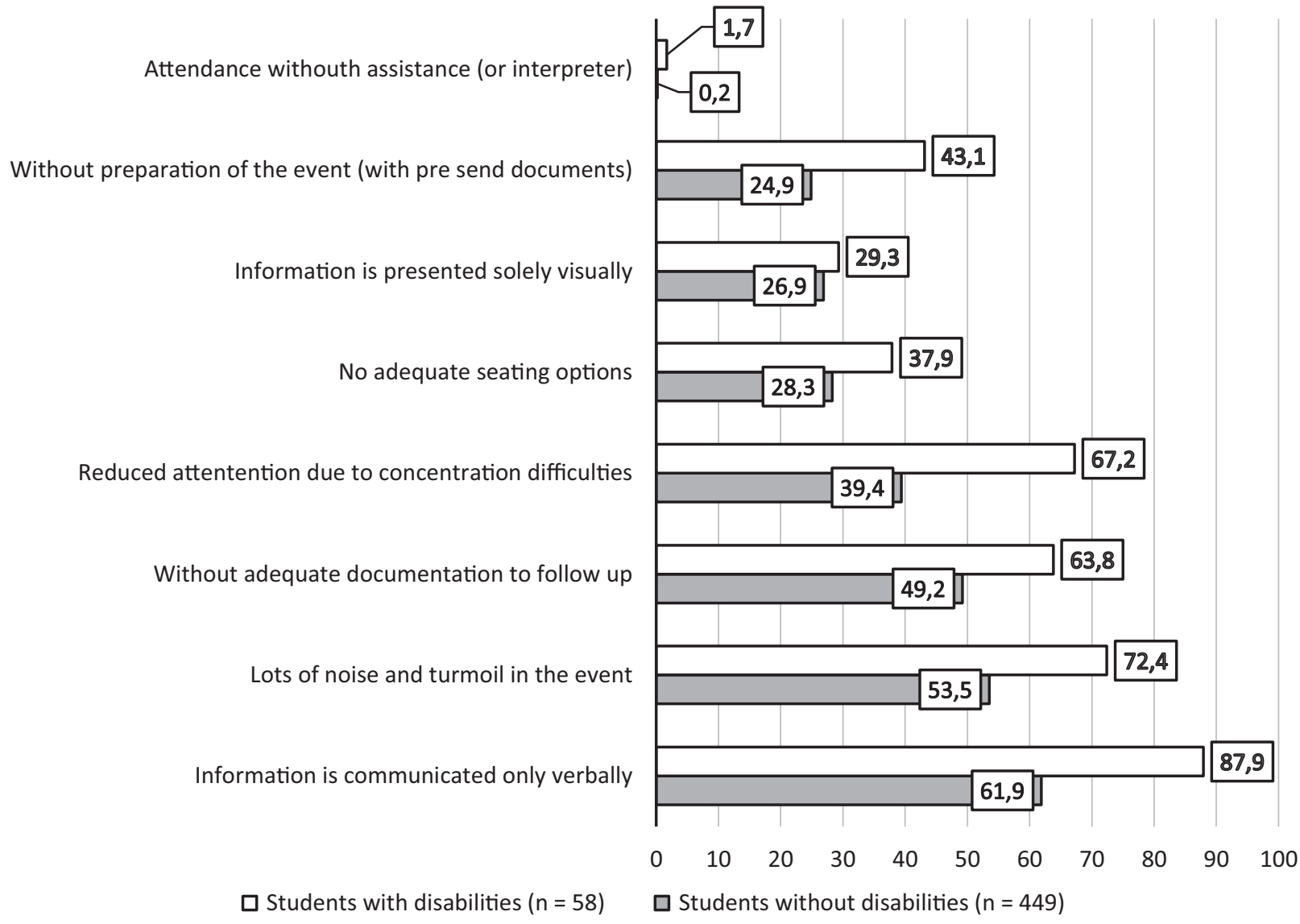

Figure 1. Information loss when participating (percentage; all students, multiple answers possible). Question: When participating in courses, I lose information if...

problems better ( $\mathrm{CrV} 0,160, \mathrm{p}=0,008$, if differentiated between different impairment types; Degree survey).

The DoBuS survey confirms the results. The majority of students with disabilities reported that they coped well with the transition to digital study (15 out of 21 ). Among the benefits of digital studying, nearly half of the students rank the item "many digital tools are more accessible than many face-to-face teaching situations" in second place behind location-independency of studying (two-thirds). Particularly those students who are blind or have visual impairments can benefit from this (8 out of 12); they also report improved access to literature (5 out of 12). For blind and visually impaired students, this means that most learning materials are accessible without time-consuming adaptations. Furthermore, the possibility of self-organising one's studies digitally is an advantage for them (DoBuS survey).

Despite these positive results, the DoBuS survey also revealed numerous barriers for students with impairments that continue to exist. That is partly due to the respective platforms and tools and partly due to the design of digital teaching by the lecturers. Recorded teaching formats, which were made available to students for time-sovereign processing, were for the most part considered unproblematic.

However, the learning platform Moodle, which is being used at TU Dortmund, was most frequently named as having accessibility problems ( 7 out of 12 blind and visually impaired students, 3 out of 5 students with mental health difficulties). Many open answers provided in the survey and various experiences from training indicate that there are problems in the platform's usability (DoBuS survey). They include issues such as the findability of content, which in the current semester predominantly refers to assignments and deadlines, as well as technically more complex assignment formats like forum discussions or mutual assessments, which are important for all students as the Degree survey shows (see Figure 2).

Surprisingly, students without impairments find many accessibility issues similarly important as students with disabilities. Significant differences can be found, especially regarding functions that are important for operations using assistive technologies (Degree survey; see Table 1).

When using or developing an accessible platform, the WCAG must be considered. It aims to improve accessibility for people with "blindness and low vision, deafness and hearing loss, limited movement, speech disabilities, photosensitivity, and combinations of these, and some accommodation for learning disabilities and cognitive limitations" (W3C, 2018). Looking at students with impairments, it often becomes evident that the largest group of students with impairment is students with 


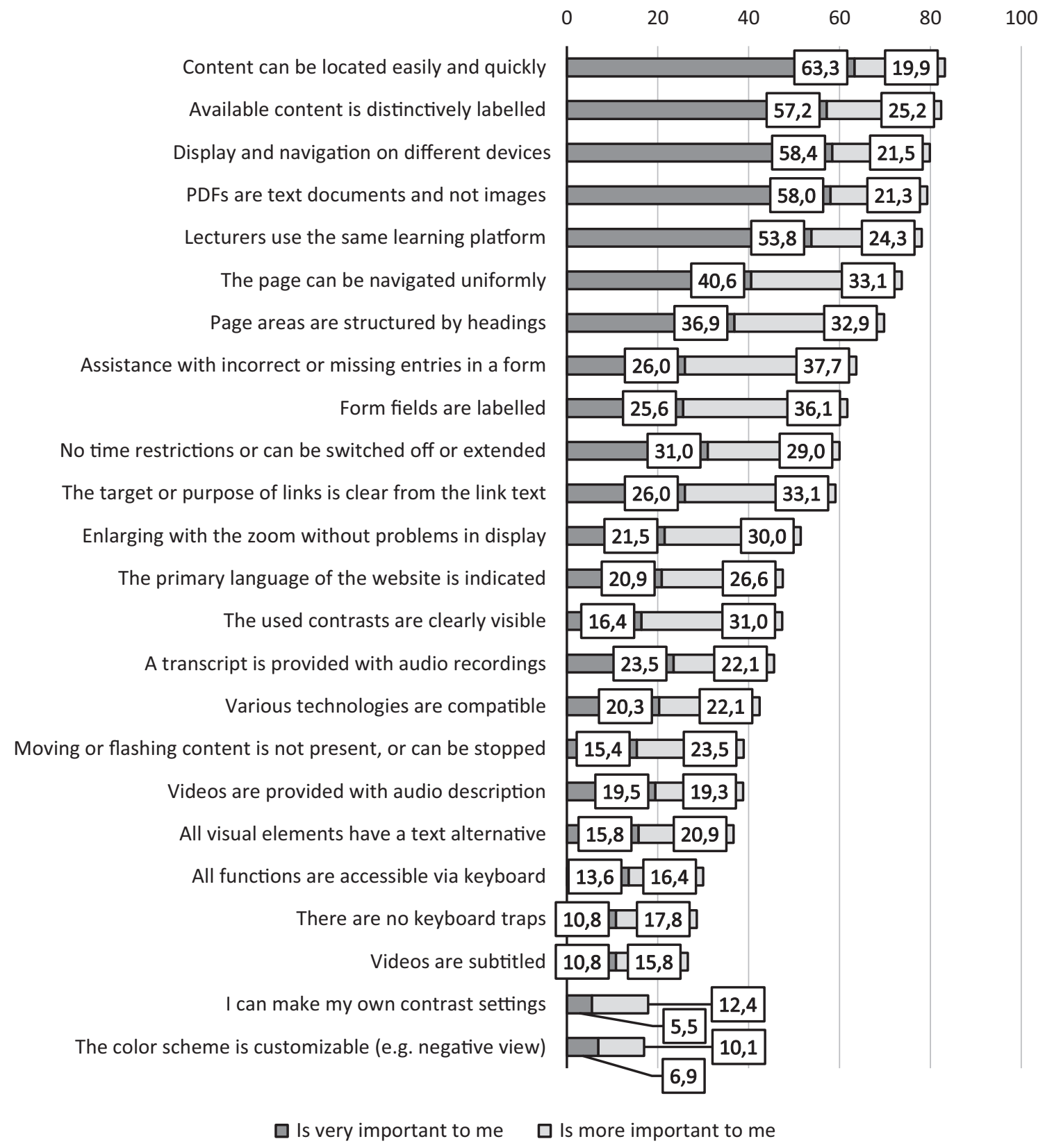

Figure 2. Importance of accessibility aspects ( $n=507$, in percent). Question: How would you rate the following statements in this context? When using e-learning offerings, the following aspects are important to me...

Table 1. Significant differences between students with and without impairments, differentiated between different impairment types (Degree survey).

\begin{tabular}{lcc}
\hline Issue & CramersV & Significance $(p)$ \\
\hline Materials clearly labelled & 0.176 & 0.002 \\
No keyboard traps & 0.172 & 0.004 \\
Subtitles/Captions & 0.171 & 0.005 \\
Text alternatives & 0.169 & 0.006 \\
Adjustable colour scheme & 0.162 & 0.018 \\
Contrast adjustments possible & 0.160 & 0.024 \\
Accessible via keyboard & 0.160 & 0.024 \\
\hline
\end{tabular}


mental health difficulties (Middendorf et al., 2017). Thus, it is vital to take a closer look at these students' answers. In the Degree survey, many partial aspects of the dimensions 'understandable' and 'operable' were rated as particularly relevant (very important and rather important):

The dimension 'operable' encompasses:

- Time limits are not present (21 out of 27 students with mental health difficulties)

- Page sections are divided by headings (24 out of 27 students with mental health difficulties)

- Materials are clearly labelled (26 out of 27 students with mental health difficulties)

- The goal or purpose of links is clear from link text (21 out of 27 students with mental health difficulties)

The dimension 'understandable' encompasses:

- There is consistent navigation (22 out of 27 students with mental health difficulties)

- Content is easy and quick to find (all students with mental health difficulties)

- Form fields are labelled (21 out of 27 students with mental health difficulties)

- Incorrect or missing information in the form is displayed, and instructions to correct errors are displayed too (21 out of 27 students with mental health difficulties)

Regarding digital teaching, communication and interaction are of particular importance. When asked which specific features students wish for in a new platform, communicative and feedback tools were named frequently $(95 \%$ name feedback from lecturers for assignments; $81 \%$ communication via text chat with fellow students; $79.5 \%$ communication via text chat with lecturers, Degree survey).

While a variety of tools offer advanced communication opportunities, problems emerge if the communicative process is being organised via learning platforms or in video conferencing systems: Students with visual impairment or blind users of assistive technology had difficulties keeping track in forums and chats. Screen reader or magnification software users are at a disadvantage in written live discussion, e.g., in chats, etherpads, etc. According to students with visual impairment, from the DoBuS survey:

Especially, when the exchange is supposed to take place live during lecture time, and many posts are posted in a short time, I can hardly follow the process.... The online interaction in my case takes mostly place via Moodle. There I find it very difficult to orient myself in the various forums and, e.g., to participate in live discussion.

\section{Discussion}

One can say the Covid-19 pandemic acted as a catalyst for digitalisation efforts at universities, not least because, until last year, those efforts at universities were not as advanced as they are now. Therefore, it is noteworthy that even though accessibility has not been the main focus of the implementation of digital tools, the majority of the students with disabilities stated that they managed this transition well.

What is also noteworthy is that many students with disabilities experienced digital study as more accessible than face-to-face study in many aspects, which confirms the assumption that the principles of UDL and UDI can be implemented and promoted through digital media (Fisseler \& Markmann, 2012). Location- and timeindependent studying and studying at one's own pace is vital for students with disabilities because they are given more flexibility to match the needs and requirements of their studies with those of their disabilities. Nevertheless, the fact that the use of digital tools is associated with an increased (time) effort for students who use assistive technologies must be considered. This underlines the importance of counselling, training and reasonable accommodation offered by universities.

The results of the Degree survey show that many accessibility rules improve teaching for all, as intended in the UD, UDL and UDI concepts. The WCAG guidelines are assigned to the four principles: perceivable, operable, understandable and robust (W3C, 2018). For most students, the guidelines of the principles operable, understandable and robust are especially important: the easy findability (retrieval) of content, clear labelling, uniform navigation, accessible PDFs and usability with different devices. That is also reflected in the high level of approval for the statement that lecturers should use the same learning platform. Accessibility and usability are closely related. Consistency and clearness contribute to users being able to achieve their goals effectively, efficiently and satisfactorily. The high level of agreement with these statements also indicates that the accessibility of platforms and tools alone does not make for accessible teaching. It also depends on a didactic concept. The content and student activities need to be designed in an inclusion-sensitive way.

Furthermore, the data indicate that communication and feedback are rated as important, but how communication can be designed in an accessible manner requires careful examination. This can be outlined as exemplary for chats: while many chats are already accessible, problems arise when using a chat for synchronous communication or during video conferences: Employing a screen reader is time-consuming as it takes more time to read and follow up with response messages, in a video conference one has to decide whether to follow the speaker or his or her screen reader, reading the messages in the chat. The importance students place on feedback raises additional questions for lecturers, such as how to provide 
every student with feedback on time (Wilkens et al., 2020). Thus, the need for an overall didactical concept in digital teaching becomes obvious. However, for this didactical concept, universal design and accessibility as guidelines to make spaces, media and learning materials that are usable for all have to be initially applied. UD and accessibility must be planned and addressed in advance. These concepts target groups and not yet the individual. For individuals, assistive technology and reasonable accommodations are important (Haage \& Bühler, 2019). Nevertheless, if a learning environment is not designed with UD and accessibility in mind, assistive technology is more difficult or even impossible to use. Findings from surveys from the digital semester 2020, such as the DoBuS and Degree survey, can be used as a starting point to develop digital teaching in an accessible manner.

\section{Conclusion}

The article aimed to contribute to answering the question of to what extent digital learning environments support equal participation in higher education. Both surveys made it clear that digital teaching can indeed be more accessible than face-to-face teaching, assuming it is developed with accessibility and UDL/UDI in mind.

However, considering accessibility and UDL/UDI in developing learning platforms and teaching is still a work in progress, with much left to do. For example, learning platforms are not yet sufficiently accessible. Moodle is an example of a widely used open-access learning platform that is being developed by a community. Obviously, too little attention is paid to the aspect of accessibility. But it is not only the platforms and tools that need to be accessible. If the concepts of higher education didactics do not change, little will be achieved. This is outlined for media use in higher education: Digital media is often associated with 'better' learning, which indicates a deterministic technology approach. But to make use of the potential digital media can offer for learning, it is necessary also to consider exams, the physical learning environment and the whole course design, rather than just single tasks (Schiefner-Rohs \& Hofhues, 2018). One can assume that this overall approach is also true for inclusive didactic. Instead of relying on the potential of digital media, this potential must be actively used.

Further research efforts on communication and collaboration via digital tools are needed. Functions and tools for communication and feedback are desired by students (Degree survey). If the communicative process is primarily organised via learning platforms (forums, chats) or video conferencing tools, problems arise for students with disabilities (DoBuS survey). Especially in collaborative tasks or in exclusively digital teaching scenarios, communication must be accessible for all. In the new research project K4D at TU Dortmund ("Collaborative Teaching and Learning with Digital Media in Teacher Education: Mobile-Professional-Inclusive"), collaborative tools and tasks are being examined for their acces- sibility. In the sense of UDL, concepts for collaborative learning with digital tools are to be developed.

Zorn (2018) postulates that in the discourse on digital teaching, the perspective on inclusion is often disregarded and vice versa. Although the potential of digital solutions for equal participation in higher education is high, these two perspectives are rarely considered together. In the research project Degree, both perspectives are considered, and the findings on accessibility from the survey influence the development of a new learning platform. The Degree survey showed once more that indeed the consideration of the principles and guidelines from the WCAG (W3C, 2018) is important for all students, not just for students with impairments. The presented findings illustrate the importance of accessible digital tools and an inclusion-sensitive didactic for equal participation in higher education. However, this requires adherence to the principles of universal design and accessibility in the selection and design of digital platforms, programs and tools.

\section{Acknowledgments}

The project on which this report is based on was funded by the BMBF Bundesministerium für Bildung und Forschung (Federal Ministry of Education and Research) under the funding code 16DHB2130. The responsibility for the content of this publication lies with the authors.

\section{Conflict of Interests}

The authors declare no conflict of interests.

\section{References}

Adams, D., Simpson, K., Davies, L., Campbell, C., \& Macdonald, L. (2019). Online learning for university students on the autism spectrum: A systematic review and questionnaire study. Australasian Journal of Educational Technology, 35(6), 111-131. https://doi.org/ 10.14742/ajet.5483

Arachchi, T. K., Sitbon, L., \& Zhang, J. (2017). Enhancing access to elearning for people with intellectual disability: Integrating usability with learning. In R. Bernhaupt, G. Dalvi, A. Joshi, D. K. Balkrishan, J. O'Neill, \& M. Winckler (Eds.), Lecture notes in computer science: Vol. 10514. Human-computer interactionINTERACT 2016: 16th IFIP TC 13 international conference, Mumbai, India, September 25-29, 2017: Proceedings (pp. 13-32). Springer. https://doi.org/ 10.1007/978-3-319-67684-5_2

Arndt, C., Ladwig, T., \& Knutzen, S. (2020). Zwischen Neugier und Verunsicherung: Interne Hochschulbefragungen von Studierenden und Lehrenden im virtuellen Sommersemester 2020 [Internal university surveys of students and faculty in the 2020 virtual summer semester]. Technische Universität Hamburg. https://doi.org/10.15480/882.3090 
Arnold, P., Kilian, L., Thillosen, A. M., \& Zimmer, G. (2018). Handbuch E-Learning: Lehren und Lernen mit digitalen Medien [Handbook e-learning: Teaching and learning with digital media] (5th ed.). W. Bertelsmann Verlag.

Bartz, J. (2020). All inclusive?! Empirical insights into individual experiences of students with disabilities and mental disorders at German universities and implications for inclusive higher education. Education Sciences, 10(9). https://doi.org/10.3390/ educsci10090223

Breitenbach, A. (2021). Digitale Lehre in Zeiten von Covid-19: Risiken und Chancen [Digital teaching in times of Covid-19: Risks and opportunities]. Pedocs, Fachportal Pädagogik. http://nbn-resolving.org/urn: nbn:de:0111-pedocs-212740

Bühler, C., Burgstahler, S., Havel, A., \& Kaspi-Tsahor, D. (2020). New practices: Promoting the role of ICT in the shared space of transition. In J. Seale (Ed.), Improving accessible digital practices in higher education: Challenges and new practices for inclusion (1st ed., pp. 117-141). Palgrave Pivot. https://doi. org/10.1007/978-3-030-37125-8_6

Burgstahler, S. (2015a). Opening doors or slamming them shut? Online learning practices and students with disabilities. Social Inclusion, 3(6), 69-79. https://doi. org/10.17645/si.v3i6.420

Burgstahler, S. (Ed.). (2015b). Universal design in higher education: From principles to practice ( 2 nd ed.). Harvard Education Press.

Burgstahler, S., Havel, A., Seale, J., \& Olenik-Shemesh, D. (2020). Accessibility frameworks and models: Exploring the potential for a paradigm shift. In J. Seale (Ed.), Improving accessible digital practices in higher education: Challenges and new practices for inclusion (1st ed., pp. 45-72). Palgrave Pivot. https://doi.org/ 10.1007/978-3-030-37125-8_3

CAST. (2018). Universal design for learning guidelines version 2.2. CAST. http://udlguidelines.cast.org

Center for Universal Design. (1997). The principles of universal design. NC State University. https://projects. ncsu.edu/www/ncsu/design/sod5/cud/about_ud/ udprinciplestext.htm

Cooper, M., Colwell, C., \& Jelfs, A. (2007). Embedding accessibility and usability: Considerations for elearning research and development projects. ALT-J Research in Learning Technology, 15(3), 231-245. https://doi.org/10.1080/09687760701673659

Dalton, E. M., Lyner-Cleophas, M., Ferguson, B. T., \& McKenzie, J. (2019). Inclusion, universal design and universal design for learning in higher education: South Africa and the United States. African Journal of Disability, 8. https://doi.org/10.4102/ajod.v8i0.519

Dannenbeck, C., Dorrance, C., Moldenhauer, A., Oehme, A., \& Platte, A. (2016). Inklusionssensible Hochschule: Zur Einführung in diesen Band [Inclusion-sensitive higher education: Introducing this volume]. In C. Dannenbeck, C. Dorrance, A. Moldenhauer, A. Oehme,
\& A. Platte (Eds.), Inklusionssensible Hochschule: Grundlagen, Ansätze und Konzepte für Hochschuldidaktik und Organisationsentwicklung [Inclusionsensitive university: Basics, approaches and concepts for university didactics and organizational development] (pp. 9-21). Verlag Julius Klinkhardt.

Directive (EU) No. 2016/2102 of 26 October 2016 of the European Parliament and of the Council on the accessibility of the websites and mobile applications of public sector bodies. (2016). Official Journal of the European Union, L 327/1.

DoBuS. (2021). Barrierefreie Medien und Assistive Technologien [Accessible media and assistive technologies]. TU Dortmund. https://dobus.zhb.tudortmund.de/studierende/barrierefreie-medienund-assistive-technologien

Edelmayer, G., \& Rauch, C. (2018). Barrierefreie Digitalität. FNMA Magazin, 4, 14-16.

Emmerdinger, K., Gegenfurtner, A., \& Stern, W. (2018). Barrierearmut an der Uni: Inklusion sehbeeinträchtigter Studierender durch die Implementierung assistiver Technologien und Universal Design in Lern-Management-Systemen [Low-barrier university: Inclusion of visually impaired students through implementation of assistive technologies and universal design in learning management systems]. Spuren-Sonderpädagogik in Bayern, 61(2), 40-43.

Fernandez, S. (2019). Making space in higher education: Disability, digital technology, and the inclusive prospect of digital collaborative making. International Journal of Inclusive Education. Advance online publication. https://doi.org/10.1080/13603116. 2019.1610806

Fichten, C. S., Asuncion, J. V., Wolforth, J., Barile, M., Budd, J., Martiniello, N., \& Amsel, R. (2012). Information and communication technology related needs of college and university students with disabilities. Research in Learning Technology, 20(4), 323-344. https://doi.org/10.3402/rlt.v20i0.18646

Fichten, C. S., Ferraro, V., Asuncion, J., Chwojka, C., Barile, M., Nguyen, M. N., Klomp, R., \& Wolforth, J. (2009). Disabilities and e-learning problems and solutions: An exploratory study. Educational Technology \& Society, 12(4), 241-256.

Fichten, C. S., Olenik-Shemesh, D., Asuncion, J., Jorgensen, M., \& Colwell, C. (2020). Higher education, information and communication technologies and students with disabilities: An overview of the current situation. In J. Seale (Ed.), Improving accessible digital practices in higher education: Challenges and new practices for inclusion (1st ed., pp. 21-44). Palgrave Pivot.

Fisseler, B., \& Markmann, M. (2012). Universal Design als Umgang mit Diversität in der Hochschule [Universal design as a way of dealing with diversity in higher education]. Journal Hochschuldidaktik, 23(1/2), 13-16. https://doi.org/10.17877/DE290R6751 
Gilch, H., Beise, A. S., Krempkow, R., Müller, M., Stratmann, F., \& Wannemacher, K. (2019). Zum Stand der Digitalisierung der Hochschulen in Deutschland in Forschung, Lehre und Verwaltung [On the state of digitization of universities in Germany in research, teaching and administration]. Qualität in Der Wissenschaft, 13(2), 34-40.

Grosch, M. (2012). Mediennutzung im Studium: Eine empirische Untersuchung am Karlsruher Institut für Technologie [Media use in studies: An empirical study at the Karlsruhe Institute of Technology]. Shaker.

Haage, A., \& Bühler, C. (2019). Barrierefreiheit [Accessibility]. In I. Bosse, J.-R. Schluchter, \& I. Zorn (Eds.), Handbuch Inklusion und Medienbildung [Handbook inclusion and media education] (1st ed., pp. 207-215). Beltz Juventa

Hochschulforum Digitalisierung. (2015).20 Thesen zur Digitalisierung der Hochschulbildung: Arbeitspapier Nr. 14 [20 theses on the digitization of higher education: Working Paper No. 14]. Hochschulforum Digitalisierung. https://hochschulforumdigitalisierung.de/ de/diskussionspapier-20-thesen-zur-digitalisierungder-hochschulbildung-arbeitspapier-14

Hochschulsport Dortmund. (2021). Sport mit Behinderung [Sports with disability]. TU Dortmund. https://hsp.tu-dortmund.de/sportangebot/sportmit-behinderung

Hofhues, S. (2020). Open Science, Open Education und offene Bildungsressource-Openness in der Sozialen Arbeit [Open science, open education and open educational resource-Openness in social work.]. In N. Kutscher, T. Ley, U. Seelmeyer, F. Siller, A. Tillmann, \& I. Zorn (Eds.), Handbuch Soziale Arbeit und Digitalisierung (1st ed., pp. 167-178). Beltz Juventa.

Kerres, M. (2020). Bildung in der digitalen Welt: Über Wirkungsannahmen und die soziale Konstruktion des Digitalen [Education in the digital world: On assumptions of impact and the social construction of the digital]. MediaEducation: Journal for Theory and Practice of Media Education, 17. https://doi.org/10.21240/ mpaed/jb17/2020.04.24.X

Köhlmann, W. (2017). Barrieren bei der Bedienung virtueller Klassenzimmer durch Blinde-Ergebnisse einer Analyse [Barriers to the operation of virtual classrooms by the blind-Results of an analysis]. In D. Bücker, A. Gumpert, U. Lucke, S. Hofhues, V. Dander, F. Rau, H. Rohland, \& T. van Treeck (Eds.), Blickpunkt Hochschuldidaktik: "Trendy, hip und cool": Auf dem Weg zu einer innovativen Hochschule? [Spotlight on higher education didactics: "Trendy, hip and cool": On the way to an innovative university?] (Vol. 130, pp. 127-139). wbv.

Krotz, F. (2014). Einleitung: Projektübergreifende Konzepte und theoretische Bezüge der Untersuchung mediatisierter Welten [Introduction: Cross-project concepts and theoretical references of the study of mediatized worlds]. In F. Krotz, C. Despotović, \& M.-M. Kruse (Eds.), Medien-Kultur-
Kommunikation. Die Mediatisierung sozialer Welten: Synergien empirischer Forschung [Media-culturecommunication. The mediatization of social worlds: Synergies of empirical research] (pp. 7-32). Springer.

Kumar, K. L., \& Owston, R. (2016). Evaluating e-learning accessibility by automated and student-centered methods. Educational Technology Research and Development, 64(2), 263-283. https://doi.org/ 10.1007/s11423-015-9413-6

Middendorf, E., Apolinarski, B., Becker, K., Bornkessel, P., Brandt, T., Heißenberg, S., \& Poskowsky, J. (2017). Die wirtschaftliche und soziale Lage der Studierenden in Deutschland 2016: 21. Sozialerhebung des Deutschen Studentenwerks durchgeführt vom Deutschen Zentrum für Hochschul-und Wissenschaftsforschung [The economic and social situation of students in germany 2016: 21st social survey of the German student union conducted by the German Center for Research on Higher Education and Science]. Bundesministerium für Bildung und Forschung.

Persike, M., \& Friedrich, J.-D. (2016). Lernen mit digitalen Medien aus Studierendenperspektive: Sonderauswertung aus dem CHE Hochschulrankung für die deutschen Hochschulen (Working Paper No. 17) [Learning with digital media from a student perspective: Special evaluation from the CHE Hochschulrankung for German universities]. Hochschulforum Digitalisierung.

Rose, D. H., \& Meyer, A. (2002). Teaching every student in the digital age: Universal design for learning. Association for Supervision and Curriculum Development.

Schiefner-Rohs, M., \& Hofhues, S. (2018). Prägende Kräfte [Formative forces]. In A. Weich, J. Othmer, \& K. Zickwolf (Eds.), Medien, Bildung und Wissen in der Hochschule [Media, education and knowledge in higher education] (pp. 239-254). Springer Fachmedien. https://doi.org/10.1007/978-3-658-17074-5_ 14

Schmid, U., Goertz, L., Radomski, S., Thom, S., \& Behrens, J. (2017). Monitor Digitale Bildung: Die Hochschulen im digitalen Zeitalter [Monitor digital education: Universities in the digital age]. Bertelsmann Stiftung. https://www.bertelsmann-stiftung.de/fileadmin/ files/BSt/Publikationen/GrauePublikationen/ DigiMonitor_Hochschulen_final.pdf

Scott, S., \& Aquino, K. (2020). Covid-19 transitions: Higher education professionals' perspectives on access barriers, services, and solutions for students with disabilities. Association on Higher Education and Disability (AHEAD). https://higherlogicdownload.s3. amazonaws.com/AHEAD/38b602f4-ec53-451c9be0-5c0bf5d27c0a/UploadedImages/COVID-19_/ AHEAD_COVID_Survey_Report_Barriers_and_ Resource_Needs_2_.docx

Scott, S., McGuire, J. M., \& Shaw, S. F. (2003). Universal design for instruction. A new paradigm for adult instruction in postsecondary education. Remedial and Special Education, 24(6), 369-379. 
Sekretariat der Kultusministerkonferenz. (Ed.). (2016). Bildung in der digitalen Welt: Strategie der Kultusministerkonferenz [Education in the digital world: Strategy of the Standing Conference of the Ministers of Education and Cultural Affairs of the federal states in the Federal Republic of Germany]. Kultusministerkonferenz. https://www.kmk.org/aktuelles/ thema-2016-bildung-in-der-digitalen-welt.html

Stabsstelle Chancengleichheit, Familie und Vielfalt. (2021). Behinderung und chronische Erkrankung [Disability and chronic disease]. TU Dortmund. https://stabsstelle-cfv.tu-dortmund.de/vielfalt/ behinderung-und-chronische-erkrankung

Steffens, Y., Schmitt, I. L., \& Aßmann, S. (2017). Mediennutzung Studierender: Über den Umgang mit Medien in hochschulischen Kontexten. Systematisches Review nationaler und internationaler Studien zur Mediennutzung Studierender [Media use by university students: On the use of media in higher education contexts. Systematic review of national and international studies on students' media use]. Universität zu Köln. https://www.pedocs.de/frontdoor. php?source_opus $=15468$

Thompson, T. (2015). Video for all. Accessibility of video content and universal design of a media player. In S. E. Burgstahler (Ed.), Universal design in higher education. From principles to practice (2nd ed., pp. 259-273). Harvard Education Press.

Traus, A., Höffken, K., Thomas, S., Mangold, K., \& Schröer, W. (2020). Stu.diCo. - Studieren digital in Zeiten von Corona [Stu.diCo.-Studying digitally in times of Corona]. Universitätsverlag Hildesheim. https://doi. org/10.18442/150

TU Dortmund. (2021a). A university with a unique profile. TU Dortmund. https://www.tu-dortmund.de/ en/university/profile

TU Dortmund. (2021b). Coronavirus: Measures at TU Dortmund university. TU Dortmund. https://www.tudortmund.de/en/coronavirus

TU Dortmund. (2021c). Department of disability and studies (DoBuS): Studying with disabilities and chronic diseases. TU Dortmund. https://www.tudortmund.de/en/students/advising-and-counseling/ studying-with-disabilities-and-chronic-diseases

United Nations Educational, Scientific and Cultural Organization. (2017). A guide for ensuring inclusion and equity in education. UNESCO. https://unesdoc. unesco.org/ark:/48223/pf0000248254

United Nations. (2008). Convention on the rights of persons with disabilities. United Nations. https://www. un.org/development/desa/disabilities/conventionon-the-rights-of-persons-with-disabilities/ convention-on-the-rights-of-persons-withdisabilities-2.html

Wilkens, L., Bühler, C., \& Bosse, I. (2020). Accessible learning management systems in higher education. In M. Antona \& C. Stephanidis (Eds.), Lecture notes in computer science. Universal access in human-computer interaction. Applications and practice (Vol. 12189, pp. 315-328). Springer International Publishing. https://doi.org/10.1007/978-3030-49108-6_23

Wilson, L., Conway, J., Martin, N., \& Turner, P. (2020). Covid-19: Disabled students in higher education: Student concerns and institutional challenges. National Association of Disability Practitioners. https://nadpuk.org/wp-content/uploads/2020/05/NADP-ReportCovid-19-Disabled-Students-in-Higher-EducationStudent-Concerns-and-Institutional-Challenges.docx

World Wide Web Consortium. (2018). Web content accessibility guidelines (WCAG) 2.1: W3C recommendation 05 June 2018. W3C. https://www.w3.org/TR/ WCAG21/\#background-on-wcag-2

Zawacki-Richter, O., Kramer, C., \& Müskens, W. (2016). Studiumsbezogene Mediennutzung im WandelQuerschnittsdaten 2012 und 2015 im Vergleich [Study-related media use in change-Cross-sectional data 2012 and 2015 in comparison]. Schriftenreihen Zum Bildungs- und Wissenschaftsmanagement, 1. https://openjournal.uni-oldenburg.de/index.php/ bildungsmanagement/article/download/101/PDF

Zhang, H., Nurius, P., Sefidgar, Y., Morris, M., Balasubramanian, S., Brown, J., Dey, A. K., Kuehn, K., Riskin, E., Xu, X., \& Mankoff, J. (2020). How does Covid-19 impact students with disabilities/health concerns? Arxiv. https://arxiv.org/pdf/2005.05438

Zorn, I. (2018). Digitalisierung als Beitrag zu einer inklusiven Hochschuldidaktik [Digitization as a contribution to inclusive university didactics]. In A. Platte, M. Werner, S. Vogt, \& H. Fiebig (Eds.), Praxishandbuch Inklusive Hochschuldidaktik [Practical handbook on inclusive university didactics] (1st ed., pp. 195-202). Beltz Juventa.

\section{About the Authors}

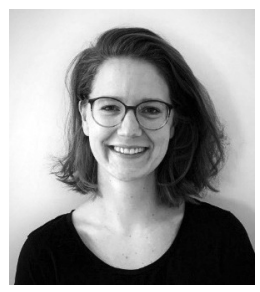

Leevke Wilkens is a Research Assistant at the Department of Rehabilitation Technology at the Department of Rehabilitation Sciences at TU Dortmund. She works in the research project "Degree 4.0Digital Teacher Education 4.0: Video-Based-Accessible-Personalized." Her scientific interests lie in the accessible digital environment in higher education and inclusive higher education. 


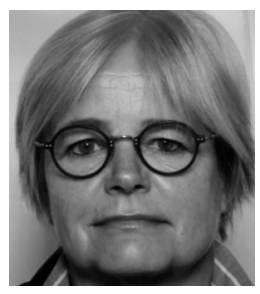

Anne Haage is a Research Assistant at the Department for Disability and Studies at TU Dortmund, responsible for digital accessibility. She works in the research project K4D ("Collaborative Teaching and Learning with Digital Media in Teacher Education: Mobile-Professional-Inclusive"). Her research fields are digital accessibility, digital participation and inclusive media education. She wrote her doctoral thesis on the information repertoire of people with disabilities (published in May 2021).

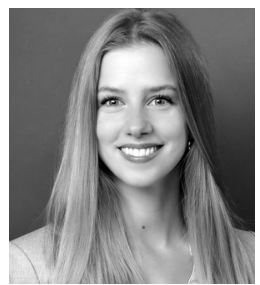

Finnja Lüttmann is a Research Assistant at the Department for Disability and Studies at TU Dortmund. She works in the research project "Degree 4.0-Digital Teacher Education 4.0: Video-BasedAccessible-Personalized." Her work and research foci are the accessible adaptation and didactic preparation of teaching and examination materials as well as university communication media, audio description and subtitling of videos, and the consulting of lecturers in the creation of accessible teaching materials.

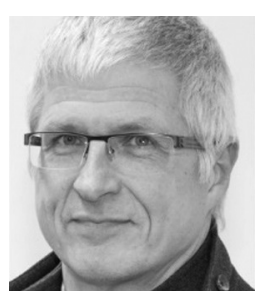

Christian R. Bühler (Prof. Dr.-Ing.) is Professor for Rehabilitation Technology and Vice Dean at the Department of Rehabilitation Sciences at TU Dortmund. He is the speaker of the Research Cluster TIP (Technology for Inclusion and Participation) for TU Dortmund. His scientific interest lies in the support of older people and people with disabilities with assistive technology, accessibility and universal design. He has more than 30 years of experience in research, education and management in the areas of accessibility, elnclusion, assistive technology and design for all. 